\title{
Autophagy induced by avian reovirus enhances viral replication in chickens at the early stage of infection
}

\author{
Xiaosai Niư ${ }^{\dagger}$ Chengcheng Zhang ${ }^{\dagger}$, Yuyang Wang, Mengjiao Guo, Baoyang Ruan, Xuefeng Wang, Tianqi Wu, \\ Xiaorong Zhang and Yantao Wu* (1)
}

\begin{abstract}
Background: Avian reovirus (ARV) is an important pathogen that can cause serious disease in poultry. Though several in vitro studies revealed some molecular mechanisms that are responsible for ARV-induced autophagy, it is still largely unknown how ARV manipulates autophagy to promote its own propagation.

Results: In this study, we demonstrated that ARV infection triggered autophagy in chicken tissues, evident from the enhancement of $L C 3-I /-||$ conversion and the appearance of abundant autophagosomes. Moreover, viral replication and the expression of IL-1 $\beta$ were coupled with the process of ARV-induced autophagy in the early stage of infection. Furthermore, regulation of autophagy affected the accumulation of LC3-II, the production of ARV and the expression of $\mathrm{IL}-1 \beta$.
\end{abstract}

Conclusions: Altogether, our data suggest that ARV induces autophagy, which benefits its replication and dissemination in chicken tissues at the early infection stage.

Keywords: Avian reovirus, Autophagy, IL-1ß, Chicken tissues

\section{Background}

Avian reovirus (ARV) is an immunosuppressive pathogen [1] that belongs to the Orthoreovirus genus in the Spinareovirinae subfamily of the Reoviridae family [2]. ARV is ubiquitous in poultry flocks, and some strains can lead to severe diseases, causing huge economic losses. The association between viral arthritis and ARV has been conclusively determined. In addition, ARV is also thought to be related to pericarditis, hepatitis, respiratory and enteric disease and malabsorption syndrome [3, 4].

Previous report revealed that ARV-induced apoptosis raises infectious virus yield [5], and several studies focused on the role of apoptosis in the pathogenesis of ARV infection [6, 7]. The tissue injury at the late stage of infection is a likely consequence of ARV-induced apoptosis, but more details about the early stage of ARV

\footnotetext{
* Correspondence: ytwu@yzu.edu.cn

${ }^{+}$Xiaosai Niu and Chengcheng Zhang contributed equally to this work. Jiangsu Co-Innovation Center for Prevention of Animal Infectious Diseases and Zoonoses, College of Veterinary Medicine, Yangzhou University, 12 East Wenhui Road, Yangzhou 225009, Jiangsu, China
}

infection need to be clarified in order to better control ARV infection. It was reported that ARV-induced autophagy, prior to apoptosis, also promotes its replication [8]. The following researches further illustrated the connection between ARV-induced autophagy and apoptosis, and identified the significance of inhibiting autophagy in the suppression of ARV replication [9-12]. In general, autophagy is an intracellular degradation process that can be triggered to confront viral infections by forming double-membraned autophagosomes targeting cytoplasmic virions or viral components and leading to autolysosomal degradation. On the other hand, viruses have evolved many strategies to manipulate the autophagy pathway, exploiting autophagy machinery for multiplication [13, 14]. Autophagy can be triggered by ARV through specific pathways [11, 15], but how ARV takes advantage of autophagy needs to be further illustrated.

A report emphasized that ARV induced inflammatory response (secretion of IL-1 $\beta$ and IL-6) and delayed apoptosis in the early stage of infection [16]. Another report indicated that activated autophagy can elevate the 


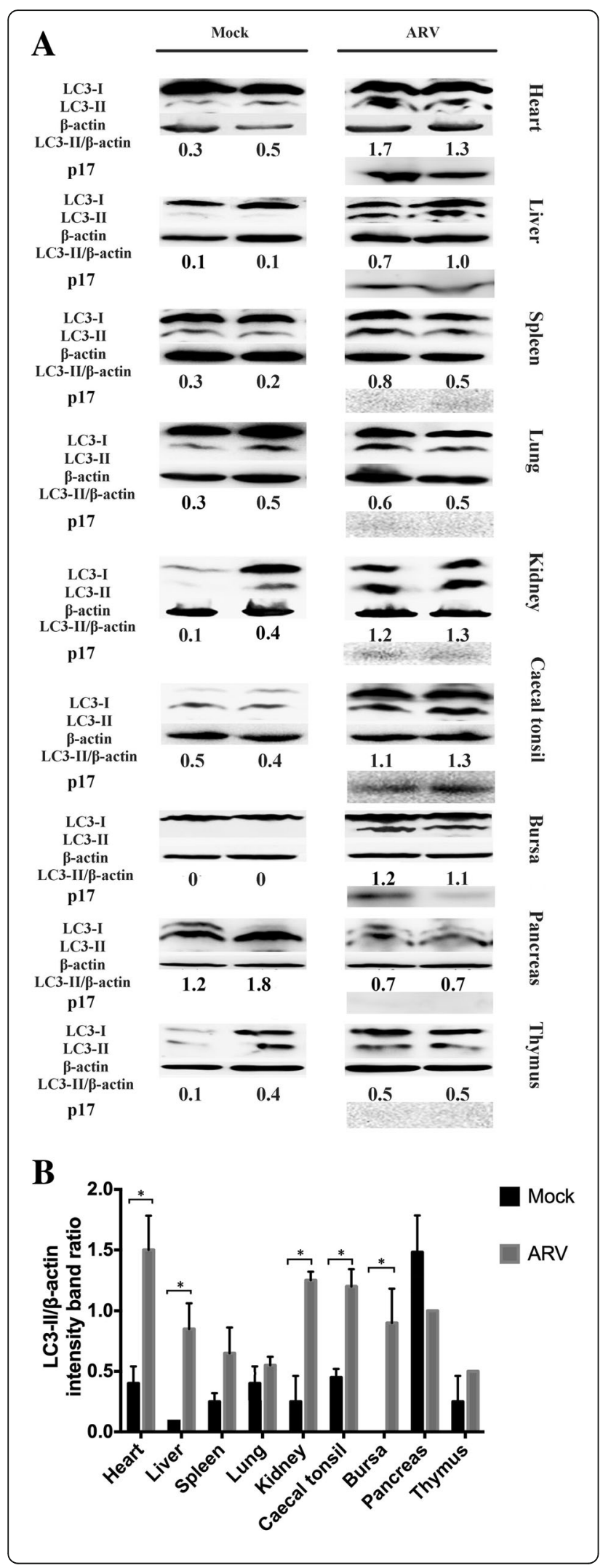

Fig. 1 Conversion of LC3-I to LC3-II in different chicken tissues. (a) The tissues were collected from Experiment I and were subjected to Western blotting analysis with anti-LC3, anti- $\beta$-actin and anti-p17 antibody. Samples of heart, liver, bursa and pancreas were loaded on a ten-lane gel with marker, and other samples were loaded on a parallel gel. (b) The relative level of LC3-II in different tissues. $\beta$-actin was used as a protein control. Significance was analyzed with multiple $t$ tests $(*, P<0.05)$

biosynthesis and secretion of the pro-inflammatory cytokine IL-1 $\beta$ [17]. In addition, our previous research also found that the expression of the receptor of IL- $1 \beta$ (IL$1 R$ ) was upregulated in the early stage of ARV infection [18]. All these findings point to a possible connection between ARV-induced autophagy and the inflammatory response, which may be helpful in explaining some symptoms in ARV infection.

As previous studies were all conducted in vitro, verifying whether ARV induces autophagy and whether it is effective to modulate autophagy to control ARV replication in complex in vivo environments are urgent research priorities.

\section{Results}

ARV infection induced autophagy in chicken tissues

To determine whether autophagy is induced upon ARV infection in vivo, Western blotting analysis was utilized to monitor the change in the abundance of LC3-II protein in the lysates of chicken tissues. After that, ultrastructural analysis of the targeted tissues was performed by Transmission electron microscopy (TEM). The data showed that, compared to uninfected tissues, the conversion from endogenous LC3-I to LC3-II was significantly increased in the heart, liver, kidney, caecal tonsil and bursa of Fabricius from the ARV-infected group (Fig. 1). Though higher amounts of LC3-II were detected in ARV-infected spleen, lung and thymus, the accumulation was not pronounced. However, the basal conversion from LC3-I to LC3-II in mock-infected pancreas was extremely high and even higher than that found in the ARV-infected groups (Fig. 1).

Following collection of data summarized above, TEM was performed on mock-treated and ARV-infected chicken tissues. We examined TEM images of the heart, caecal tonsil and bursa and found that the doublemembrane vesicles, in which cytosolic components or organelles were sequestered, were significantly increased in ARV-infected tissues compared with mock-infected tissues (Fig. 2). As depicted in Fig. 2a and c, accumulated autophagosomes were observed in ARV-infected cardiac myocytes and were absent in uninfected cells. Mitochondria with abnormal appearances, such as swelling, disorganization and reduction or vanishing of the cristae, were also observed (Fig. 2b). The gap between 

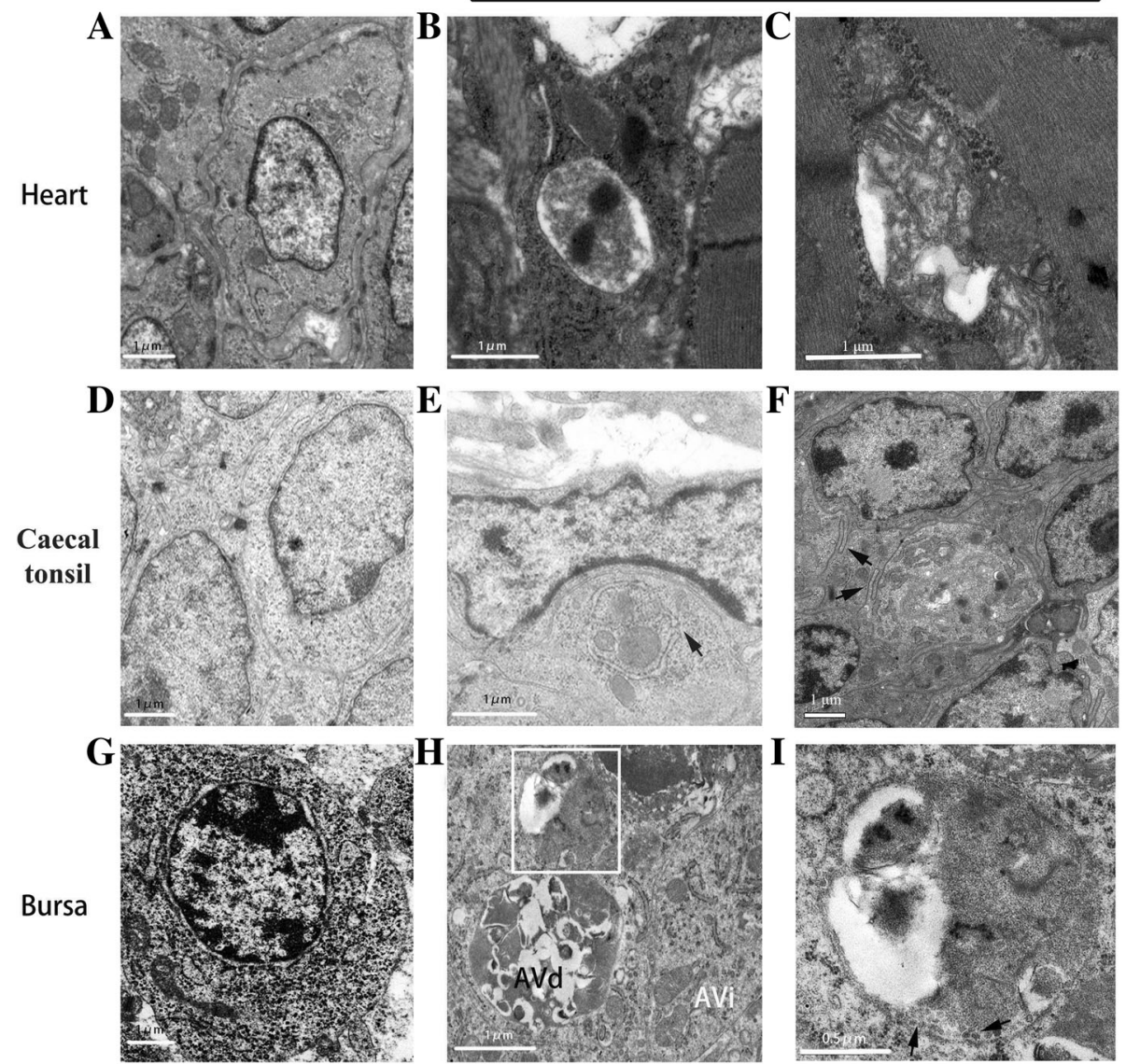

Fig. 2 TEM observation of heart, caecal tonsil and bursa. The mock-infected cells $(\mathbf{a}, \mathbf{d}, \mathbf{g})$ are shown in the first column, and the ultrastructure images of ARV-infected tissues are listed in the second and third columns. Bars, $1 \mu \mathrm{m}(\mathbf{a}$ to $\mathbf{h})$ and $0.5 \mu \mathrm{m}$ (i). Arrows indicate the growing double membrane

myocardial fibers was filled with autophagic structures (Fig. 2c). The amounts of autophagosomes observed in ARV-infected caecal tonsils were also greater than those present in normal cells (Fig. 2d and f). The precursor of the autophagosome, termed the phagophore, in which portions of the cytoplasm and mitochondria were sequestered, was clearly shown in Fig. 2e, with an incompletely closed double-membrane structure (indicated by the arrow). Several autophagic vacuoles at different stages of degradation were discovered in ARVinfected bursal cells, and early initial autophagic vacuole (AVi) and degradative autophagic vacuole (AVd) are shown (Fig. 2h). The AVi can be identified by its contents (morphologically intact cytoplasm, including rough endoplasmic reticulum and mitochondria) and the limiting membrane that is partially visible as two bilayers separated by a narrow electron-lucent cleft. The AVd can be identified by its contents and partially degraded, electron-dense rough ER [19]. The tangentially sectioned inner membrane was also detected (indicated by the arrow in the enlarged Fig. 2i).

\section{ARV triggered autophagy and promoted the expression of IL- $1 \beta$ along with virus propagation}

To study the development of autophagy in ARV-infected tissues, different time points were set to investigate the accumulation of LC3-II. As shown in Fig. 3, the amounts of LC3-II protein in the heart, caecal tonsil and bursa at different time points were analyzed by Western blotting. In summary, the conversion of LC3-I to LC3-II in ARV-infected tissues reached the highest level at $72 \mathrm{hpi}$ and showed a significant difference compared with uninfected tissues. The increased production of LC3-II could be sustained up to $96 \mathrm{hpi}$ in caecal tonsil (Fig. 3d).

The viral load in ARV-infected tissues at different time points was determined by $\mathrm{TCID}_{50}$ assay. As shown in Fig. 4, ARV replicated well and was most abundant in infected hearts, caecal tonsils and bursae 


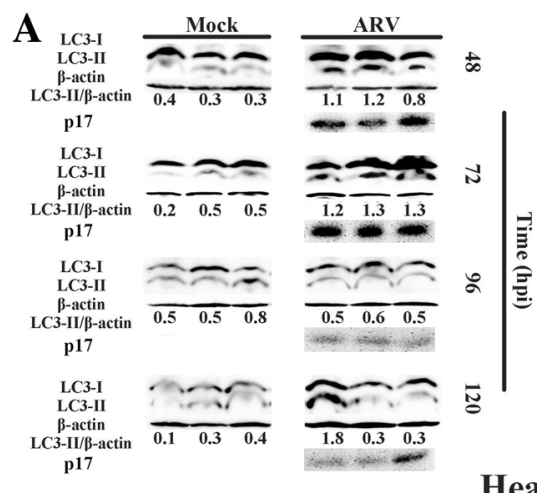

Heart

C
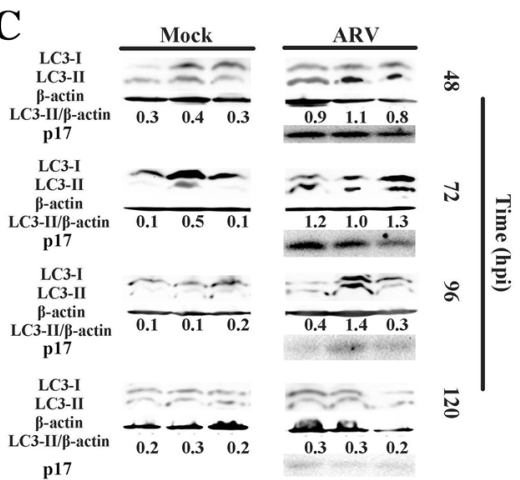

Caecal tonsil

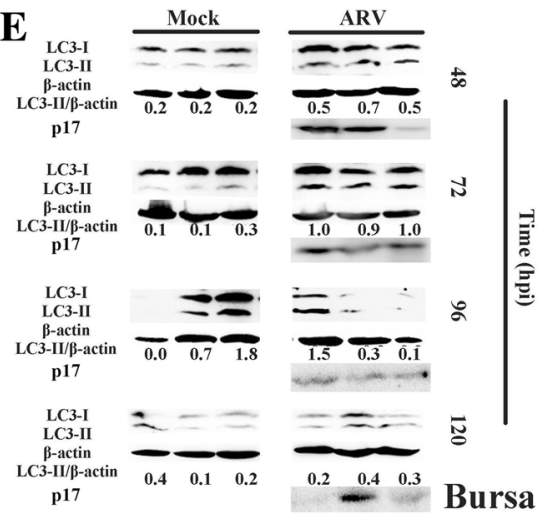

B

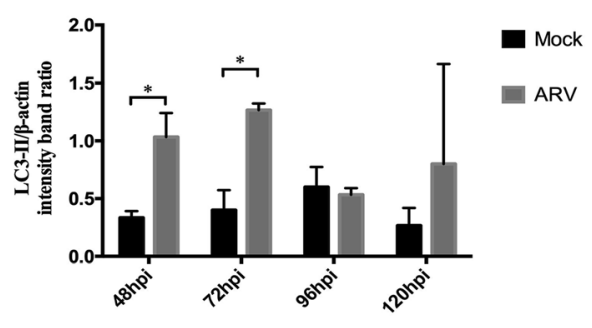

D

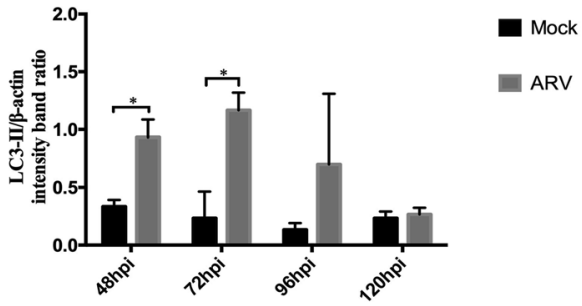

F

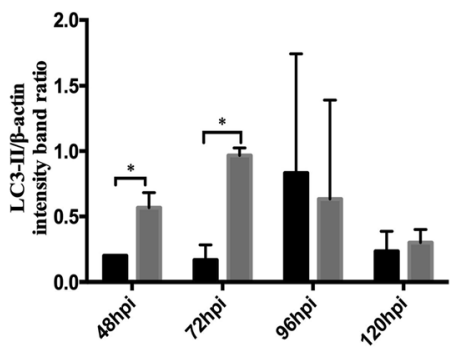

Mock

ARV

Fig. 3 Conversion of LC3-I to LC3-II in heart (a, b), caecal tonsil $(\mathbf{c}, \mathbf{d})$ and bursa $(\mathbf{e}, \mathbf{f})$ at different time points. The tissues were collected from Experiment II at the indicated time points and were subjected to Western blotting analysis. $\beta$-actin was used as a protein control and p17 was detected. Significance was analyzed with multiple t tests $(*, P<0.05)$

at 72 hpi. At the same time point, autophagy peaked. After 72 hpi, the virus titers showed distinct declining trends. The replication of ARV in the heart dwindled slowly but declined rapidly in bursa. On the other hand, ARV sustained effective replication in the caecal tonsil for a longer period (96 hpi).

To evaluate the pro-inflammatory response in ARV-infected tissues, the expression levels of IL-1 $\beta$ were calculated by RT-qPCR and are shown as fold changes in Fig. 5. The relative expression levels of IL-1 $\beta$ were almost the same across different time points in mock-infected tissues, and the averages were designated as 1 . In ARV-infected hearts, the expression of IL-1 $\beta$ reached a peak value at $72 \mathrm{hpi}$, while the most severe hydropericardium was observed when the chicks were sacrificed at $72 \mathrm{hpi}$ (data not shown). The variation in trends of the relative expression levels of IL-1 $\beta$ in the caecal tonsil and bursa were similar to those in the heart. In the bursa, although the fold value was the lowest, the absolute mRNA quantity of IL-1 $\beta$ was the most abundant (data not shown). 


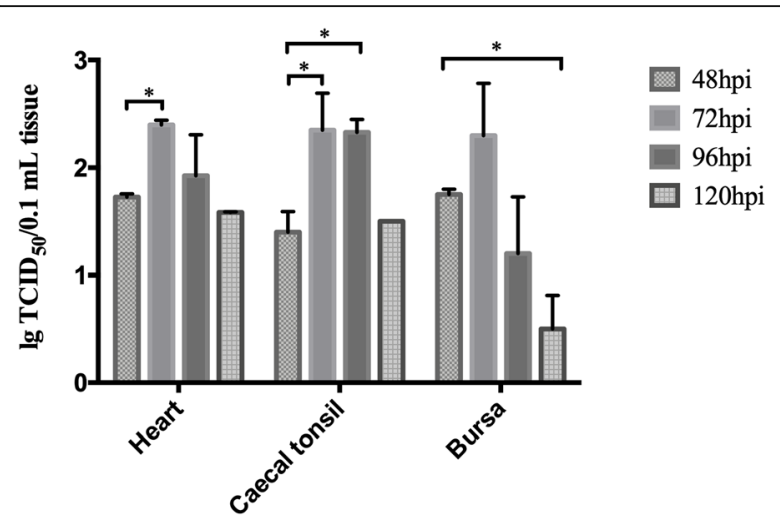

Fig. 4 The viral load in ARV-infected heart, caecal tonsil and bursa at different time points. The ARV-infected tissues were collected from Experiment II at the indicated time points, and the virus yields were determined by $\mathrm{TCID}_{50}$ in CEF cells. Significance was analyzed with two-way ANOVA $\left({ }^{*}, \mathrm{P}<0.05\right)$

\section{Modulation of autophagy influenced ARV replication in chicken tissues}

The prior data showed a correlation between ARV replication and autophagy, and more experiments were performed to validate the role of autophagy in ARV replication in vivo. Chloroquine (CQ), which can block the formation of autolysosomes and lead to the accumulation of LC3-II at the late stage of autophagy [8], was used as an inhibitor of autophagy. The amounts of LC3II, the viral load of ARV and the expression of IL-1 $\beta$ in different tissues were calculated as described above.

The data (Fig. 6a) showed that ARV-induced the accumulation of LC3-II. Upon treatment with CQ, the degradation of LC3-II was blocked. As shown in Fig. 6b, compared with independent ARV infection, CQ treatment inhibited ARV replication, especially in bursa.

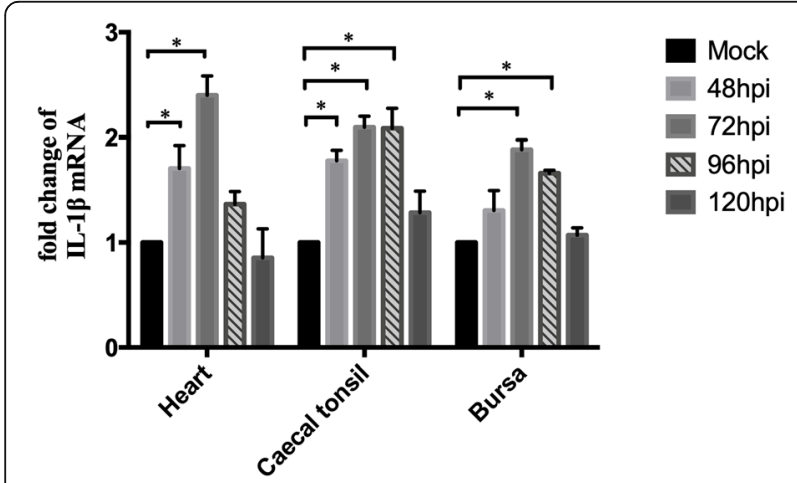

Fig. 5 The relative expression levels of IL-1 $\beta$ in heart, caecal tonsil and bursa at different time points. The tissues were collected from experiment $\mathrm{II}$ at the indicated time points. The average relative expression levels of $I L-1 \beta$ in mock-infected tissues were designated as 1. The expression levels of IL-1 $\beta$ in ARV-infected tissues are shown as the fold change. Significance was analyzed with two-way ANOVA $(*, P<0.05)$
Although no significant differences were detected in heart and caecal tonsil between the ARV-infected and CQ-treated groups, CQ treatment reduced the viral load by approximately half compared with independent ARV infection in all checked tissues. Furthermore, CQ treatment remarkably lessened the ARV-induced expression of IL-1 $\beta$ (Fig. 7).

\section{Discussion}

In this study, we examined ARV-induced autophagy in different chicken tissues at the early stage of infection. The LC3 proteins are involved in phagophore formation and are the most widely monitored autophagy-related proteins [19]. The accumulation of LC3-II and the appearance of autophagosomes in ARV-infected heart, caecal tonsil and bursa of Fabricius were particularly notable (Figs. 1 and 2). The intestine-associated lymphoid tissues, such as caecal tonsil and bursa, are thought to be primary viral replication sites after oral inoculation of ARV [6]. Two early studies indicated that ARV could penetrate the intestine by infecting certain epithelial cells, which might be intestinal microfold cells that overlie the lymphoid tissues and interact with the immune system [20,21]. After prior infection, the replication of ARV and the expression of IL- $1 \beta$ were correlated with the development of autophagy in these immune tissues (Figs. 3 and 5). Autophagy can be stimulated by ARV infection and plays a positive role in ARV replication [8, 14]; then, activated autophagy contributes to the biogenesis and secretion of IL-1 $\beta$ [17]. Consequently, more immune cells are recruited and can be infected [22-24] and carry ARV into the circulatory system.

Pericarditis or myocarditis can be common in ARV infection [3]. The results of this report showed that the conversion of LC3-I to LC3-II was most significant in the heart, and the classical structural features of autophagy (mitochondrial damage) were observed in myocardial tissue (Figs. 1 and 2). A previous study of mammalian reovirus (MRV) identified that MRV only causes cytopathogenic effects in cardiac myocytes but not in cardiac fibroblasts, which is thought to be the determinant of reoviral myocarditis [25]. The severe autophagy combined with the secretion of IL-1 $\beta$ (Fig. 5) may be one of the important inducements of the myocarditis in ARV infection.

Blocking the formation of autolysosomes by CQ led to more accumulation of LC3-II and greatly reduced the viral load in ARV-infected tissues (especially in bursa) (Fig. 6). These results are in accordance with in vitro studies $[8,9]$. Except that, CQ treatment significantly decreased the ARV-induced expression of IL-1 $\beta$ in all detected tissues (Fig. 7). The data in this study suggests the relationship between autophagy and ARV infection in 

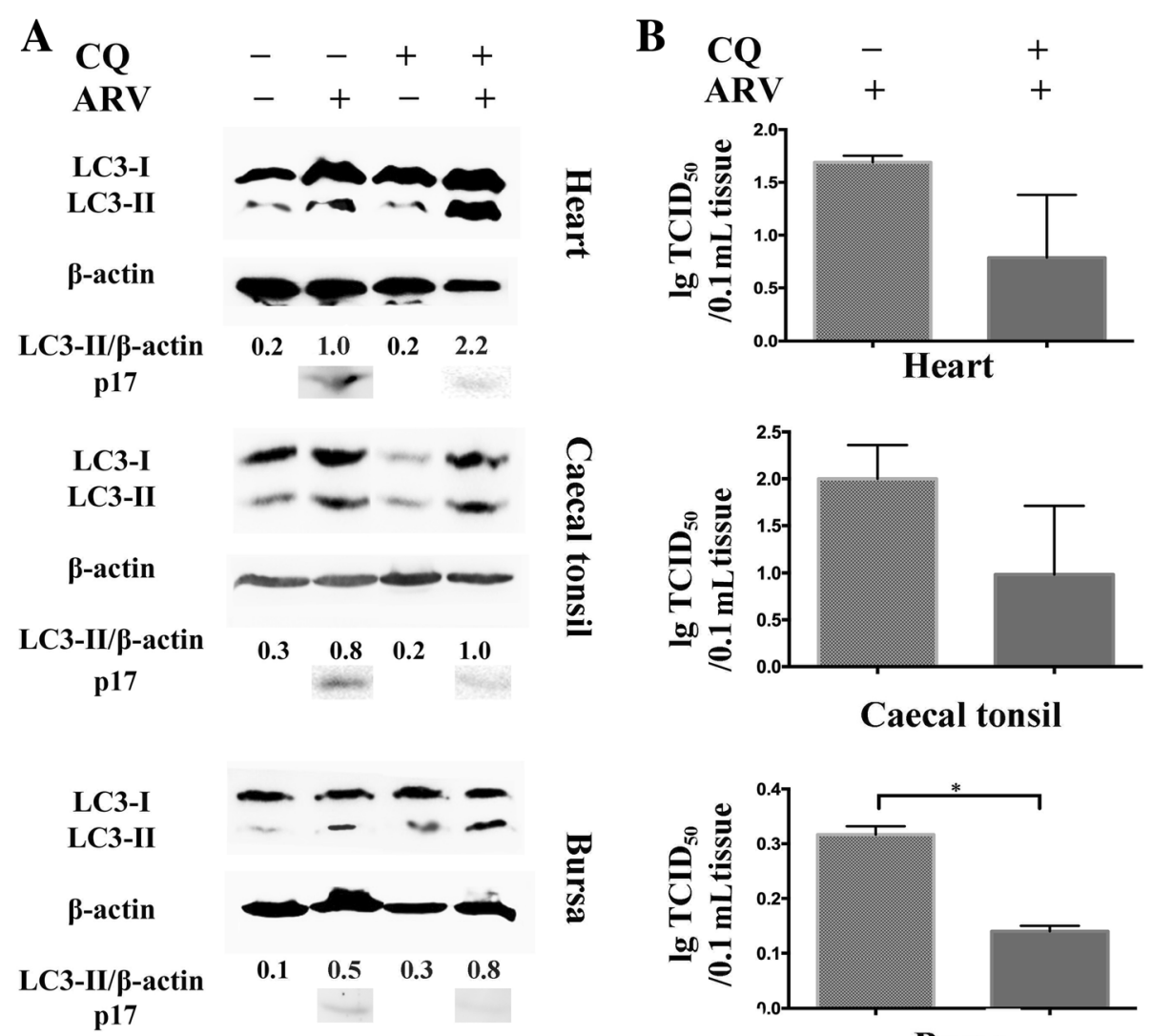

Caecal tonsil

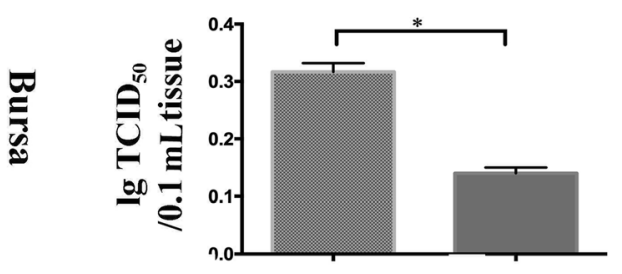

Bursa

Fig. 6 The effect of autophagy on ARV replication in heart, caecal tonsil and bursa. The tissues were collected from Experiment III. The amounts of LC3-II and p17 (a) and the viral load (b) in heart, caecal tonsil and bursa under different treatments were detected. Significance was analyzed with $t$ tests $(*, P<0.05)$

vivo, but more detailed mechanisms need to be further studied.

\section{Conclusions}

In conclusion, autophagy is utilized to promote viral replication at the early stage of ARV infection. These

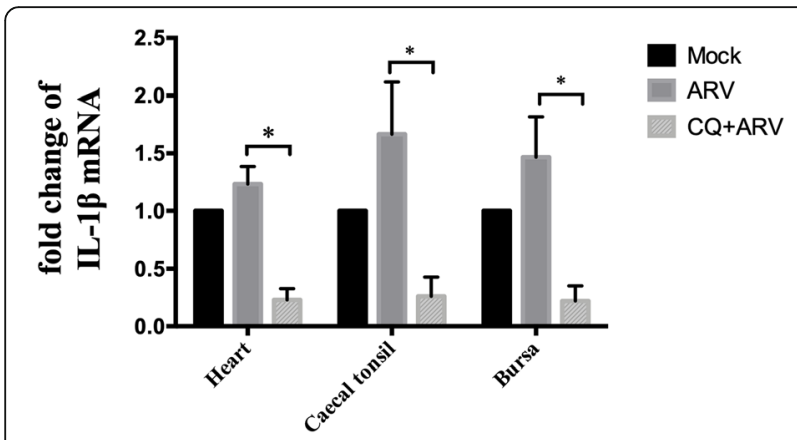

Fig. 7 The effect of autophagy on the relative expression levels of $\mathrm{IL}-1 \beta$ in heart, caecal tonsil and bursa. The tissues were collected from Experiment III. The relative expression levels of $I L-1 \beta$ in mockinfected tissues were designated as 1 . The expression levels of IL-1 $\beta$ in ARV-infected tissues are shown as the fold change. Significance was analyzed with two-way ANOVA $\left({ }^{*}, P<0.05\right)$ results may be helpful for understanding the molecular mechanisms underlying ARV infection and pathology.

\section{Methods}

Antibodies and reagents

Monoclonal antibody against p17 was prepared by our lab. CQ, antibodies against LC3 or $\beta$-actin and horse radish peroxidase-labeled secondary antibodies were purchased from Sigma-Aldrich (Shanghai, China). RIPA lysis buffer, PMSF and SDS-PAGE loading buffer were purchased from Beyotime Biotechnology (Shanghai, China). Chemiluminescent substrate was purchased from Thermo Fisher Scientific (Shanghai, China).

\section{Cells and virus}

Chicken embryonic fibroblast (CEF) cells were prepared from 10-day-old specific-pathogen-free (SPF) chicken embryos and cultured in M199 medium (Gibco, Shanghai, China) supplemented with $3 \%$ newborn calf serum (Gibco) and $1 \%$ penicillin-streptomycin (Gibco). Cells adhering to plates at $37^{\circ} \mathrm{C}$ and $5 \% \mathrm{CO}_{2}$ were used for cell culture passage. ARV strain GX/2010/1 was propagated in CEF cells, and the titer was determined as the 
median tissue culture infective dose $\left(\mathrm{TCID}_{50}\right)$ as described previously [26]. The complete genomic sequence of the ARV strain GX/2010/1 was deposited in GenBank (accession numbers KJ476699-KJ476708).

\section{Animal handling}

SPF chicken embryonated eggs were purchased from Boehringer Ingelheim Vital Biotechnology (Beijing, China) and hatched under a controlled temperature $\left(37.8^{\circ} \mathrm{C}\right)$ and humidity $(60 \%)$. The chickens were housed in cages with free access to food and water during the study. The ARV-infected chickens and the mockinfected chickens were placed in different rooms. The animal experiments were carried out under "Laboratory animals-General requirements for animal experiment" (GB/T 35823-2018, China). The chickens were euthanized by injection of air in intracranial, and the best effort was employed to minimize the pain. A completed ARRIVE guidelines checklist is included in Additional file 1 .

\section{Animal experiments}

Experiment I was designed to distinguish whether autophagy would be induced and to measure the levels of autophagy in different tissues after inoculation with ARV. Four 1-day-old chicks were randomly and equally divided into two groups. The ARV-infected group was inoculated orally with $10^{7} \mathrm{TCID}_{50} \mathrm{ARV}(0.1 \mathrm{~mL})$, and the negative control group was treated with an equal volume of phosphate buffered saline (PBS). At $48 \mathrm{~h}$ post inoculation (hpi), the heart, liver, spleen, lung, kidney, caecal tonsil, bursa of Fabricius, pancreas and thymus were collected for further investigation.

Experiment II was designed to estimate the variation tendency of autophagy, the viral load and the inflammatory response with time. Twenty-four 1-day-old chicks were randomly and equally divided into two groups and were treated as previously described in Experiment I. Three chicks from each group were sacrificed every $24 \mathrm{~h}$ from 48 hpi. The heart, caecal tonsil and bursa of each chick were collected for Western blotting analysis, viral load determination and reverse transcriptionquantitative PCR (RT-qPCR).

Experiment III was designed to verify the roles of autophagy in ARV propagation. Twelve 1-day-old chicks were randomly and equally divided into four groups. Three groups were set as control groups, and the chicks were treated with PBS, CQ $(20 \mathrm{mg} / \mathrm{kg})$ or $10^{7} \mathrm{TCID}_{50}$ ARV. Group 4 was set as an autophagy-inhibited group and was treated as described previously [27, 28]. Briefly, the chicks were injected intraperitoneally with CQ (20 $\mathrm{mg} / \mathrm{kg}) 2 \mathrm{~h}$ before oral inoculation with $10^{7} \mathrm{TCID}_{50}$ ARV. The injection of CQ $(20 \mathrm{mg} / \mathrm{kg})$ was performed every $12 \mathrm{~h}$. At $72 \mathrm{hpi}$, all chicks were sacrificed and handled as previously described in Experiment II.

\section{Western blotting}

Western blotting was performed as described previously [28] with minor modification in sample preparation. In our research, equal amounts of tissues were collected on ice, and homogenized in ice-cold RIPA lysis buffer supplemented with $1 \mathrm{mM}$ PMSF. The lysates were cleared by centrifugation for $5 \mathrm{~min}$ at $12000 \mathrm{rpm}$ at $4{ }^{\circ} \mathrm{C}$, and the supernatants were further denatured by incubation with SDS-PAGE loading buffer at $100{ }^{\circ} \mathrm{C}$ for $10 \mathrm{~min}$. Then, equal amounts of protein samples were applied for the Western blotting assay. The immunoreactive bands were incubated with the enhanced chemiluminescent substrate and visualized with a Tanon imager. The LC3 and $\beta$-actin were detected on one blot, while p17 was detected on parallel blot. All images were only adjusted with brightness and contrast. Densitometry analysis of the expression of LC3-II and $\beta$-actin was performed using ImageJ software (National Institutes of Health, Bethesda, MD, United States). All Western blotting experiments were performed twice.

\section{Transmission electron microscopy}

TEM was used to observe autophagy and could show autophagy in context with its complex cellular environment at subcellular resolution [21]. For ultrastructure analysis, normal and infected tissues, including the heart, caecal tonsil and bursa, were collected from Experiment I and used for TEM observation as described previously [29]. Polymerized thin sections, approximately 60-80 $\mathrm{nm}$, were cut, stained on the grid, examined and photographed with a CM-100 transmission electron microscope (Philips) at $100 \mathrm{kV}$.

\section{Viral load determination}

After ARV infection, equal amounts of tissues collected from Experiment II and III were mixed and homogenized with $600 \mu \mathrm{L}$ of PBS. The homogenates were frozen and thawed three times to release the virus. The cellular remains were eliminated by centrifugation at $8000 \mathrm{rpm}$ for $10 \mathrm{~min}$ at $4{ }^{\circ} \mathrm{C}$. The supernatants of infected tissues were harvested and serially diluted 10 -fold in serum-free medium. These mixtures were used to inoculate CEF cells in 96-well plates to determine TCID $_{50}$ per milliliter of original supernatant.

\section{RT-qPCR}

Total RNA was extracted from the tissues collected from Experiment II using the TRIzon reagent RNA kit (CWbio, Beijing), and reverse transcription was performed for cDNA using the HiScriptII 1st Strand cDNA Synthesis Kit (plus gDNA wiper) (Vazyme, Nanjing) 
Table 1 Primers used in this study

\begin{tabular}{|c|c|c|c|}
\hline Primer pairs & Sequences & Reference & Standard curves \\
\hline IL-1 $\beta-F$ & GTGAGGCTCAACATTGCGCTGTA & \multirow[t]{2}{*}[28]{} & \multirow{2}{*}{$\begin{array}{l}y=-3.45 x+31.16 \\
R=-1.000, \text { error }=0.005\end{array}$} \\
\hline$I L-1 \beta-R$ & TGTCCAGGCGGTAGAAGATGAAG & & \\
\hline$\beta$-actin- $F$ & GAGAAATTGTGCGTGACATCA & \multirow[t]{2}{*}[29]{} & \multirow{2}{*}{$\begin{array}{l}y=-3.82 x+37.84 \\
R=-0.998, \text { error }=0.016\end{array}$} \\
\hline$\beta$-actin- $R$ & GAGAAATTGTGCGTGACATCA & & \\
\hline
\end{tabular}

according to the manufacturer's recommendations. The concentration of total RNA was measured using a spectrophotometer (NanoDrop 2000c, Thermo), and $2 \mu \mathrm{g}$ of RNA was used for cDNA synthesis in $20 \mu \mathrm{L}$ volume. The primers for IL- $1 \beta$ and reference gene $\beta$-actin used in RT-qPCR were described previously $[30,31]$ and are listed in Table 1. The optimized PCR mixture consisted of $10 \mu \mathrm{L}$ Top Green qPCR SuperMix (TransGen, Beijing), $0.25 \mu \mathrm{M}$ of each primer, $2 \mu \mathrm{L} \mathrm{cDNA}$ and $7 \mu \mathrm{L}$ $\mathrm{H}_{2} \mathrm{O}$. The thermal cycling conditions consisted of an initial denaturation step at $94{ }^{\circ} \mathrm{C}$ for $20 \mathrm{~s}$, followed by 1 cycle plus 40 cycles of $94^{\circ} \mathrm{C}$ for $10 \mathrm{~s}$ and $63{ }^{\circ} \mathrm{C}$ for $30 \mathrm{~s}$. The melting curve was determined in three steps: $95^{\circ} \mathrm{C}$ for $15 \mathrm{~s}, 60^{\circ} \mathrm{C}$ for $1 \mathrm{~min}$, and then heating to $95^{\circ} \mathrm{C}$.

To determine the relative mRNA expression level of IL-1 $\beta$, the standard curves of IL- $1 \beta$ and $\beta$-actin were constructed by 1:10 diluted linearized (digested by ApaI) standard plasmids based on the $p E A S Y$-T3 cloning vector (TransGen, Beijing) and are listed in Table 1. The $\beta$ actin gene was used as a reference gene for cDNA normalization.

\section{Statistical analysis}

Data were expressed as the means \pm standard deviations. Significance was determined with multiple $t$ tests or two-way ANOVA (*, $P<0.05$ ). All statistical tests were performed with GraphPad Prism 6.0.

\section{Additional file}

Additional file 1: The ARRIVE Guidelines Checklist. (DOCX $659 \mathrm{~kb})$

\section{Abbreviations}

ARV: Avian reovirus; AVd: Degradative autophagic vacuole; AVi: Initial autophagic vacuole; CEF: Chicken embryonic fibroblast; CQ: Chloroquine: hpi: Hours post inoculation; MRV: Mammalian reovirus; PBS: Phosphate buffered saline; RT-qPCR: Reverse transcription-quantitative PCR; SPF: Specificpathogen-free; $\mathrm{TCID}_{50}$ : The median tissue culture infective dose; TEM: Transmission electron microscopy

\section{Acknowledgements}

Not applicable.

\section{Authors' contributions}

$\mathrm{XN}$ and $\mathrm{CZ}$ conceived and designed the experiments. XN, YW1 and BR performed the experiments. XN, MG and TW analyzed the data. XW and XZ contributed reagents/materials. XN, CZ, XZ, YW2 wrote the manuscript. All authors read and approved the final manuscript.

\section{Funding}

This work was financially supported by National Natural Science Foundation of China (31272576) and the China Agriculture Research System (CARS-40K16) in the design of the study, collection, analysis, and interpretation of data; 'High-end talent support program' of Yangzhou University and the Priority Academic Program Development of Jiangsu Higher Education Institutions (PAPD) in writing the manuscript.

\section{Availability of data and materials}

All data analysed during this study are included in this published article. The raw data generated during the current study are available from the corresponding author on reasonable request.

\section{Ethics approval and consent to participate}

All procedures, care and maintenance of animals were approved by the Committee on the Ethics of Animal Experiments of Yangzhou University.

\section{Consent for publication}

Not applicable.

\section{Competing interests}

The authors declare that they have no competing interests.

Received: 31 January 2019 Accepted: 20 May 2019

Published online: 24 May 2019

References

1. Schat KA, Skinner MA. Avian immunosuppressive diseases and Immunoevasion. In: Avian Immunology. Edited by Schat KA, Kaspers B, Kaiser P, second edition edn: Academic Press; 2014: 275-297.

2. King AMQ, Adams MJ, Carstens EB, Lefkowitz EJ. Virus taxonomy: classification and nomenclature of viruses: ninth report of the international committee on taxonomy of viruses. Waltham: Academic Press, London; 2012.

3. Ayalew LE, Gupta A, Fricke J, Ahmed KA, Popowich S, Lockerbie B, Tikoo SK, Ojkic D, Gomis S. Phenotypic, genotypic and antigenic characterization of emerging avian reoviruses isolated from clinical cases of arthritis in broilers in Saskatchewan, Canada. Scientific Reports. 2017;7(1):3565.

4. Nham EG, Pearl DL, Slavic D, Ouckama R, Ojkic D, Guerin MT. Flock-level prevalence, geographical distribution, and seasonal variation of avian reovirus among broiler flocks in Ontario. The Canadian veterinary journal $=$ La revue veterinaire canadienne. 2017;58(8):828.

5. Chulu JL, Lee LH, Lee YC, Liao SH, Lin FL, Shih WL, Liu HJ. Apoptosis induction by avian reovirus through p53 and mitochondria-mediated pathway. Biochem Biophys Res Commun. 2007;356(3):529-35.

6. Lin HY, Chuang ST, Chen YT, Shih WL, Chang CD, Liu HJ. Avian reovirusinduced apoptosis related to tissue injury. Avian Pathology. 2007:36(2):155-9.

7. Lin PY, Liu HJ, Chang CD, Chang Cl, Hsu JL, Liao MH, Lee JW, Shih WL. Avian reovirus S1133-induced DNA damage signaling and subsequent apoptosis in cultured cells and in chickens. Arch Virol. 2011;156(11):1917-29.

8. Meng S, Jiang K, Zhang X, Zhang M, Zhou Z, Hu M, Yang R, Sun C. Wu Y. avian reovirus triggers autophagy in primary chicken fibroblast cells and Vero cells to promote virus production. Arch Virol. 2012;157(4):661-8.

9. Duan S, Cheng J, Li C, Yu L, Zhang X. Autophagy inhibitors reduce avianreovirus-mediated apoptosis in cultured cells and in chicken embryos. Arch Virol. 2015;160(7):1679.

10. Lin PY, Chang CD, Chen YC, Shih WL. RhoA/ROCK1 regulates avian Reovirus S1133-induced switch from autophagy to apoptosis. BMC Vet Res 2015, 11(1):1-12. 
11. Chi PI, Huang WR, Lai IH, Cheng CY, Liu HJ. The p17 nonstructural protein of avian reovirus triggers autophagy enhancing virus replication via activation of phosphatase and tensin deleted on chromosome 10 (PTEN) and AMP-activated protein kinase (AMPK), as well as dsRNA-dependent protein kinase (PKR). J Biol Chem. 2013;288(5):3571-84.

12. Huang WR, Chiu HC, Liao TL, Chuang KP, Shih WL, Liu HJ. Avian Reovirus protein p17 functions as a nucleoporin Tpr suppressor leading to activation of p53, p21 and PTEN and inactivation of PI3K/AKT/mTOR and ERK signaling pathways. PLoS One. 2015;10(9):e0138627.

13. Dong $X$, Levine B. Autophagy and viruses: adversaries or allies? Journal of Innate Immunity. 2015;5(5):480-93.

14. Wang Y, Jiang K, Zhang Q, Meng S, Ding C. Autophagy in negative-Strand RNA virus infection. Front Microbiol. 2018:9.

15. Huang WR, Chi Pl, Chiu HC, Hsu JL, Nielsen BL, Liao TL, Liu HJ. Avian reovirus p17 and $\sigma A$ act cooperatively to downregulate Akt by suppressing mTORC2 and CDK2/cyclin A2 and upregulating proteasome PSMB6. Sci Rep. 2017;7(1).

16. Lin PY, Liu HJ, Liao MH, Chang CD, Chang Cl, Cheng HL, Lee JW, Shih WL. Activation of PI 3-kinase/Akt/NF-kB and Stat3 signaling by avian reovirus $\mathrm{S} 1133$ in the early stages of infection results in an inflammatory response and delayed apoptosis. Virology. 2010;400(1):104-14.

17. Dupont N, Jiang S, Pilli M, Ornatowski W, Bhattacharya D, Deretic V. Autophagy-based unconventional secretory pathway for extracellular delivery of IL-1 $\beta$. EMBO J. 2011;30(23):4701-11.

18. Niu X, Wang Y, Min L, Zhang X, Wu Y. Transcriptome analysis of avian reovirus-mediated changes in gene expression of normal chicken fibroblast DF-1 cells. BMC Genomics. 2017:18(1):911.

19. Klionsky DJ, Abdelmohsen K, Abe A, Abedin MJ, Abeliovich H, Arozena AA, Adachi H, Adams CM, Adams PD, Adeli K. Guidelines for the use and interpretation of assays for monitoring autophagy. 3rd ed; 2016.

20. Jones RC, Islam MR, Kelly DF. Early pathogenesis of experimental reovirus infection in chickens. Avian Pathology Journal of the Wvpa. 1989;18(2):23953.

21. Tang KN, Fletcher OJ, Villegas $P$. The effect on newborn chicks of oral inoculation of reovirus isolated from chickens with tenosynovitis. Avian Dis. 1987:31(3):584-90.

22. Chen YS, Shen PC, Su BS, Liu TC, Lin CC, Lee LH. Avian reovirus replication in mononuclear phagocytes in chicken footpad and spleen after footpad inoculation. Can J Vet Res. 2015;79(2):87-94.

23. Mills JN, Wilcox GE. Replication of four antigenic types of avian reovirus in subpopulations of chicken leukocytes. Avian Pathology. 1993;22(2):353-61.

24. Wu YF, Liu HJ, Shien JH, Chiou SH, Lee LH. Characterization of interleukin1 beta mRNA expression in chicken macrophages in response to avian reovirus. J Gen Virol. 2008;89:1059-68.

25. Baty CJ, Sherry B. Cytopathogenic effect in cardiac myocytes but not in cardiac fibroblasts is correlated with reovirus-induced acute myocarditis. J Virol. 1993;67(10):6295-8.

26. Yu L, Zhang X, Wu T, Su J, Wang Y, Wang Y, Ruan B, Niu X, Wu Y. Avian infectious bronchitis virus disrupts the melanoma differentiation associated gene 5 (MDA5) signaling pathway by cleavage of the adaptor protein MAVS. BMC Vet Res. 2017:13(1):332.

27. Sun Y, Li C, Shu Y, Ju X, Zou Z, Wang H, Rao S, Guo F, Liu H, Nan W. Inhibition of autophagy ameliorates acute lung injury caused by avian influenza a H5N1 infection. Sci Signal. 2012;5(212):ra16.

28. Sun Y, Yu S, Ding N, Meng C, Meng S, Zhang S, Zhan Y, Qiu X, Tan L, Chen H. Autophagy benefits the replication of Newcastle disease virus in chicken cells and tissues. J Virol. 2014;88(1):525.

29. Du J, Wang L, Wang Y, Shen J, Pan C, Meng Y, Yang C, Ji H, Dong W. Autophagy and apoptosis induced by Chinese giant salamander (Andrias davidianus) iridovirus (CGSIV). Vet Microbiol. 2016:195:87-95.

30. Barjesteh N, Hodgins DC, St Paul M, Quinteiro-Filho WM, DePass C, Monteiro MA, Sharif S. Induction of chicken cytokine responses in vivo and in vitro by lipooligosaccharide of campylobacter jejuni HS:10. Vet Microbiol. 2013; 164(1-2):122-30

31. Li YP, Bang DD, Handberg KJ, Jorgensen PH, Zhang MF. Evaluation of the suitability of six host genes as internal control in real-time RT-PCR assays in chicken embryo cell cultures infected with infectious bursal disease virus. Vet Microbiol. 2005;1 10(3-4):155-65

\section{Publisher's Note}

Springer Nature remains neutral with regard to jurisdictional claims in published maps and institutional affiliations.

\section{Ready to submit your research? Choose BMC and benefit from:}

- fast, convenient online submission

- thorough peer review by experienced researchers in your field

- rapid publication on acceptance

- support for research data, including large and complex data types

- gold Open Access which fosters wider collaboration and increased citations

- maximum visibility for your research: over $100 \mathrm{M}$ website views per year

At $\mathrm{BMC}$, research is always in progress.

Learn more biomedcentral.com/submissions 